\title{
On Training Methods of Five Basic Skills of College English
}

\author{
Jun Shu \\ English Department, Zhenjiang Watercraft College of PLA, No. 130 Taohuawu Road, Zhenjiang 212003, China \\ Email: shujun97@yahoo.com.cn
}

\begin{abstract}
In accordance with the latest College English Curriculum Requirements issued by the National Depart of Education in 2007, the objective of College English is to develop Students' ability to use English in a well-rounded way, especially in listening and speaking, so that in their future studies and careers as well as social interactions they will be able to communicate effectively and improve their general cultural awareness so as to meet the needs of China's social development and international exchanges. To achieve the objective of College English, the training methods of five basic skills of College English are discussed in this essay.
\end{abstract}

Index Terms - five basic skills, college English, training methods

\section{INTRODUCTION}

College English, an integral part of higher learning, is a required basic course for undergraduate students. In accordance with the latest College English Curriculum Requirements issued by the National Depart of Education in 2007, the objective of College English is to develop Students' ability to use English in a well-rounded way, especially in listening and speaking, so that in their future studies and careers as well as social interactions they will be able to communicate effectively and improve their general cultural awareness so as to meet the needs of China's social development and international exchanges. To achieve the objective of College English mentioned above, the training methods of five basic skills of College English are discussed as follows:

\section{TRaining Methods on Five Basic SKILls of College English}

\section{A. Training on Listening Skills}

No one can deny the fact that listening plays a very important role in learning foreign languages and in the daily interpersonal communication. Therefore, listening holds an essential status in the teaching of College English. However, upon entering College, students are quite different in the aspect of standards of listening skills. In the whole, the majority of students have barely received any rigid and systematic training on listening, which results in their lack of abilities on distinguishing English sounds. To solve the problem, the method of dictation is advised to adopt in order to rapidly improve students listening skills within a short period of time.

1. Difficulty of content and the speed of broadcast should be taken into account while selecting material for listening

Just as mentioned above, new college students are lack of listening skills and they are weak in their ability to distinguish English sounds. So, it is necessary to conduct constant practice on distinguishing and correcting English sounds at the initial stage of listening class. It is practicable to select listening materials containing easy English words, English phonetic symbols or the combination of the both.

2. Secondly, with students' abilities to distinguish English sounds improving, listening materials containing single sentences can be selected. The practice of dictation on single sentences can be implemented by different groups with each group containing 10 to 15 single sentences. The length, difficulty and the speed of the single sentences is fully determined by students' performance on the training. In the beginning, comparatively simple sentences are provided. With listening practices keep going on, the length and the difficulty of single sentences can be improved bit by bit and the speed of the single sentence can also be increased accordingly.

3. Lastly, little essays can be offered for students to practice on dictation. In the course of transition from single sentences to listening to short essays, a variety of hints can be suggested to students in order to lower their difficulty in listening comprehension.

In summary, the implementation of the method of dictation at the early stage of college English listening class is helpful for developing students' abilities to deal with language information and laying down solid foundations on improving students' listening skills. The proper use of the method can help students improve their listening skills within a short period of time.

\section{B. Training on Oral English}

With the rapid development of China's robust export-oriented economy and culture in the world stage, College Students' ability of oral English is increasingly emphasized by both the national higher education departments as well as 
students themselves. Tests on college students oral English have been included in CET-4, which shows the direction of how to conduct practice on oral English. A great major of college students have some difficulty in oral English expression upon entering the college. In view of the situation, it is suggested that the following method can be adopted so as to improve college students' oral English ability as soon as possible.

1. Lay a good foundation on English Sounds

It is known that English sound is the foundation of English language. Students' ability of oral English is directly affected by uttering English sound correctly. It is necessary to conduct systematic practice on the correction of uttering English words at early stage of college life because quite a number of students could not pronounce English words correctly. The practice on the correction of uttering English words can be arranged on the listening class using various ways, such as tongue twisters, poems, simple English songs and so on. For example, in the course of learning plosive /p/ and $/ \mathrm{b} /$, the following tongue twisters can be used for practice: Peter is picking pears and pumpkins; Betty Bother bough some butters. Meanwhile, poem reading is also a good way to practice English sounds as many poems contain very touching and music-like rhythm.

2. Retell short stories and brief dialogues already learned in the listening class.

The short stories and brief dialogues which have been already learned in the early period of listening class are extremely appropriate materials for conducting oral English practice because they are basically interesting in content and short in length. At first, it is not easy for students to open their mouth in the class actively due to their fear or shyness. It is teachers' responsibility to encourage students to open their mouths at all means. Even if students can not speak a complete sentence, the utterance of several key words in the sentence is equally worthy of warm praise from the teacher. However, with frequent and constant practice on oral English going on, it can be expected that students' inner confidence on oral English will become stronger and stronger, which will result in their corresponding enhancement in their oral English ability.

3. Have a three-minute oral report in English before English class formally starts.

Before English class formally starts, a three-minute English speech will be delivered by one student on duty. The content of English speech is non-obligatory. The speaker can discuss any topic as he wishes. He can talk about recent events at home or abroad and give his personal opinion on diversified issues that interest him/her.

\section{Training on Reading Comprehension}

The College English Curriculum Requirements points out that the top priority of College English teaching is to cultivate students' relatively-strong ability on reading comprehension, which fully shows the importance of reading comprehension. CET-4 has four requirements on reading comprehension: a. grasp the main idea of the passage b. find the facts and details leading to the topic or the main theme of the passage c. understand the literal meaning of the passage and in the meantime make reasonable judgment and inference based on the passage d. understand the meaning of some particular sentences in the passage and also understand the logic relationship of the context. To meet the requirements mentioned above, students must learn some reading skills and techniques. The following methods of developing reading skills are suggested as follows:

\section{1. skimming}

Skimming is one of the very useful reading skills that the reader only grasps the main idea of the passage without paying attention to every detail mentioned in the passage. The following three methods can be adopted to help increase the speed of skimming: a. to skim a passage, it is necessary to read the first two paragraphs of the passage at a faster speed in order to determine the main idea, background or theme of the passage as well as the writing style of the author. b. while skimming, it is important to find the top sentence and get the main idea of each paragraph. c. to achieve the quicker reading speed, skimming should be conducted by reading the passage in idea groups instead of reading the passage word by word or sentence by sentence.

2. consultation

Consultation is also one of the very useful reading skills that the reader picks up some particular information from abundance of words in the passage. Several points should be noted when consultation is adopted: a. determine the information you wants to look for and its form $\mathrm{b}$. learn to find the location of particular information in the passage $\mathrm{c}$. learn to look for the information by way of glimpse at the passage.

3. read-up

Read-up is such a kind of reading skill that the reader reads the passage very carefully. Read-up requires the reader to have a complete and thorough understanding of the meaning of the passage. Several points should be paid attention to when read-up is used: a. determine the main idea of the passage b. make correct inference based on the main idea of the passage $c$. figure out the meaning of unfamiliar words according to the context $d$. to introduce the main idea of each paragraph based on the sentence structure and writing style of the passage.

In all, the above-mentioned reading skills are not exclusive from each other because reading is the process of incorporating numerous reading skills and techniques. To understand a passage well, it is necessary to use the above-mentioned reading skills in a proper and flexible way.

\section{Training on Writing}

It is known to all that the development of students' competence in English language and mentality can be fully 
reflected in their writing. How to improve students' writing skill is undoubtedly a hot topic worthy of constant exploration for English teachers and English researchers. Training on how to write well are mainly focused on three aspects: vocabulary, sentences and the paragraph(passage).

1. Vocabulary

Vocabulary is the key to writing well. So, teachers are supposed to carry out vocabulary teaching through the whole process of text learning. The concrete ways are:

(1). to conduct practice on relevant words

Teachers offer another words and phrases that are relevant to the words appearing in each text and ask students to complete sentences with proper forms of the words and phrases offered.

(2). to actively use the words just learned

Teachers ask students to make sentences using the key words which students have just learned in the text. By making sentences using the key words, students will have a better grasp of the usage of the new words.

(3). to conduct practice on frequently used collation of some new words

In addition to understanding the meaning of some words, students are also required to understand some frequently used collation of some words. The foresaid ways of vocabulary teaching will lay a solid foundation for the improvement of students' writing skills.

2. Sentences

With the increase in students' vocabulary, teachers are supposed to conduct single sentence training for students. Writing good single sentences is essential to writing well. Several points can not fail to neglect:

1) the unity of the sentence should be emphasized, that is, each sentence is allowed to have only one key point however long or short the sentence is;

2) the meaning of the sentence should be clearly expressed by the sentence and the sentence should be logical.

3) complete the sentence pattern using idiomatic English instead of Chinglish

4) the sentence should be simple and concise

5) the sentence should be balanced instead of top-heaviness

6) the wording of the sentence should be carefully considered to achieve the accurate and vivid effect.

Through single sentence writing, students can develop good habit of writing and finally they can write out sentences which are grammatically correct and full of expressive force as well.

3. paragraphs/passage

A group of sentence organized carefully in the order of logical development will constitute a paragraph. Generally speaking, a paragraph is made up of one topic sentence, one reasoning sentence and one end sentence. How to write a paragraph well? Here are some suggestions.

1) the fundamental function of the topic sentence is to express directly and clearly the main idea of the paragraph, so, simple and concise sentence should be employed as topic sentence.

2) students should be frequently reminded that all reasoning sentences must concentrate on the main theme of the paragraph without writing sentence irrelevant with the main theme of the paragraph. Besides, teachers need to ask students to pay attention to the variety of the sentences and the usage of transition words so that the smoothness and vividness of the sentence can be achieved.

3 ) the key to writing end sentence well lies in the grasp of key words in the topic sentence and answer the questions enacted by the topic sentence. Based on the rigid and steady writing training in the order of vocabulary, single sentence and to paragraph, students are definitely expected to improve their writing skills to a great extent.

\section{E. Training on Translation}

It is my personal opinion that for a long time College English teachers have not paid enough attention to translation. As a result, students have shown insufficient ability in translation. As a matter of fact, translation is a relatively complex language activity which concerns dealing with two different cultural backgrounds at the same time. The training on translation skills is provided as follows:

1. The key to translation is to accurately understand the content of the translated material.

Before doing the job of translation, translator is supposed to have a thorough and accurate understanding of the content of the translated material otherwise errors in translation are unavoidable. Accurate understanding of the content of the translated material can be analyzed from word meaning and language environment.

1) analysis of word meaning

a. one important feature of English words is that it may contain different meaning in different context. translator not only pay attention to the concept meaning of the word but also note its associative meaning for example, in the phrase accept a university chair, here, the concept meaning of chair is a kind of instrument for someone to sit in ,but in this phrase, the associative meaning of chair should be considered, it should be interpreted as a position. So the whole meaning of the phrase can be explained as this: he agrees to be engaged in teaching in the university.

b. translation should pay attention to the influence that social and cultural background exert on the language. For another example, how to understand the following sentence, George's Waterloo was a woman. It is known to all Waterloo is the location where the French Emperor Napoleon suffered great failure in the battlefield. Afterwards, the word Waterloo was borrowed to indicate the meaning of failure. So the sentence means that George was totally ruined 
by a woman.

c. translator should be aware of the usage of English idioms and old sayings in the language. For example You say that it is out of question, but it seems to me that it is out of the question. In this sentence, two phrases "out of question" and "out of the question" are English idioms which possess exactly opposite meaning. For another example it rains dogs and cats. It will be ridiculous to translate the sentence literally without knowing the meaning of the old saying "rain cats and dogs".

2) analysis of language environment

Language environment includes both context where the sentence lies and also the social background that the sentence reflects. It is incorrect to neglect the social background which the sentence reflects while doing the job of translation. For example The Japanese burned houses, robbed the wealth of people and raped woman. Considering the crimes that the Japanese soldiers have committed to the Chinese people during the Second World War, that is, considering the social background that the sentence reflects, it is good to translate the Japanese as the Japanese s devil.

2. The essence of translation is to fully express the content of the translated material.

No one denies that the first step of translation lies in the accurate understanding of the translated material while the essence of translation is to fully express the content of the translated material. Translator will not only express the original meaning that the author tries to convey but also demonstrate the soul of the translated material. In order to achieve the objectives mentioned before, students are required to master the principles of two languages and have a good command of two languages. The combination of expressing fully on the basis of understanding and deepening understanding in the course of expression will bring forward a great progress in students' translation abilities.

\section{CONCLUSION}

In summary, the five basic skills of listening, speaking, reading, writing and translating are infiltrative and promotive to each other. Teachers should be fully aware of the significance of the training of the five basic skills of college English on College English teaching at the basic stage.

\section{REFERENCES}

[1] Department of Education, PRC. (2007). College English Curriculum Requirements. Beijing: Tsinghua Publishing House, 20-30.

[2] Gairns, R. and Redman, S. (2006). Working with Words. Cambridge: Cambridge University Press, 60-63.

[3] Gage, N. and Berliner, D. (1991). Educational Psychology. (5 ${ }^{\text {th }}$ ed). Boston: Houghton, Mifflin, 279-290.

[4] Gou Honglan. (2001). Culture Knowledge and Instruction on Reading. Journal of Xian International Studies University, (3), 56-60.

[5] Hu Wengzhong. (1995). Dictionary of British and American Culture. Beijing: Beijing Foreign Language Teaching and Research Publishing House, 200-210.

[6] Li Shaoshang.(2001). Dictation: An effective means of foreign languages teaching. Journal of PLA University of Foreign Languages, (4), 65-74.

[7] Yan Chunhai and Zhang Meijuan. (2002). Affective Factors in Foreign Language Teaching. Foreign Language World, (5), 80-92.

[8] Wang Zuoliang and Ding Wangdao. (1987). An Introduction to the Study on English Styles. Beijing: Beijing Foreign Languages Teaching and Research Publishing House. 120-140.

Jun Shu was born in Zhenjiang, Jiangsu Province, China in 1969. He received his M.A. degree in English linguistics from PLA Foreign Languages University in 2004.

He is currently an associate professor in the PLA Zhenjiang Watercraft College, Zhenjiang, Jiangsu Province, China. His research interests include English teaching methods and American Education.

$\mathrm{Mr}$. Shu is a member of the Chinese Association of Foreign Language Teachers. 